\title{
Discovering Common Pathogenic Mechanisms of COVID-19 and Parkinson Disease: an Integrated Bioinformatics Analysis
}

\section{Aria Jahanimoghadam}

Universität Würzburg: Julius-Maximilians-Universitat Wurzburg

Hadis Abdolahzadeh

Royan Institute

Niloofar Khoshdel rad

Royan Institute

Javad Zahiri ( $\nabla$ jzahiri@health.ucsd.edu )

University of California San Diego https://orcid.org/0000-0002-8360-2458

\section{Research Article}

Keywords: COVID-19, Parkinson disease, transcriptome analysis, regulatory networks, signaling pathways, Bioinformatics

Posted Date: March 3rd, 2022

DOI: https://doi.org/10.21203/rs.3.rs-1340295/v1

License: (9) This work is licensed under a Creative Commons Attribution 4.0 International License. Read Full License 


\section{Abstract}

Coronavirus disease 2019 (COVID-19) has emerged since December 2019 and was later characterized as a pandemic by WHO, imposing a major public health threat globally. Our study aimed to identify common signatures from different biological levels to enlighten the current unclear association between COVID-19 and Parkinson's disease (PD) as a number of possible links and hypotheses were reported in the literature. We have analyzed transcriptome data from peripheral blood mononuclear cells (PBMCs) of both COVID-19 and PD patients, resulting in a total of 81 common differentially expressed genes (DEGs). The functional enrichment analysis of common DEGs are mostly involved in the complement system, type II interferon signaling (IFNG) pathway, oxidative damage, microglia pathogen phagocytosis pathway, GABAergic synapse. The protein-protein interaction network (PPIN) construction was carried out followed by hub detection, revealing 10 hub genes (MX1, IFI27, C1QC, C1QA, IFI6, NFIX, C1S, XAF1, IFI35, and $E L A N E)$. Some of the hub genes were associated with molecular mechanisms such as Lewy bodiesinduced inflammation, microglia activation, and cytokine storm. We investigated regulatory elements of hub genes at transcription factor and microRNA levels. The major transcription factors regulating hub genes are SOX2, XAF1, RUNX1, MITF, and SPI1. We propose that these events may have important roles in the onset or progression of PD. To sum up, our analysis describes possible mechanisms linking COVID19 and PD, elucidating some unknown clues in between.

\section{Introduction}

According to the statistics provided by WHO, there have been approximately 255 Million cases diagnosed with coronavirus disease in 2019 (COVID-19) with more than 5 million confirmed death cases as of November 2021. The novel severe acute respiratory syndrome coronavirus 2 (SARS-CoV-2) causes COVID-19 and is considered a worldwide pandemic whose impacts are noticeable across the globe (Chams et al. 2020; Khorsand et al. 2020). COVID-19 is initially viewed as a respiratory disease. However, it was demonstrated that SARS-CoV-2 affects multiple organs such as the central nervous system (CNS). Moreover, neurological manifestation associated with SARS-CoV-2 can potentially occur via direct invasion of the virus into CNS and thus, introduce the brain as a location containing high replicative values for SARS-CoV-2 (Song et al. 2021; Szcześniak et al. 2021).

PD (Parkinson's disease) is a neurodegenerative disease characterized for the first time in 1817 by James Parkinson. However, after nearly two centuries of research, the cause of most of the cases is still unclear (Olsen et al. 2018; Hayes 2019). There are multiple reports regarding the occurrence of neurological complications in individuals with COVID-19 as up to $85 \%$. Additionally, hyposmia, one of the symptoms of PD, has been reported to happen in $65 \%$ of cases with COVID-19 (Merello et al. 2021). The prevalence of PD among elderly ages higher than 65 is $1-3 \%$ and for the whole population is approximately $0.3 \%$ (Raza et al. 2019). Of note, PD is distinguished mainly via degeneration of dopaminergic neurons located in the substantia nigra of the midbrain (Kalia and Lang 2016). Subsequently, a number of theoretical mechanisms such as basal ganglia injury, microglial-induced inflammation, and post-encephalopathy inflammation have been proposed to be the hypothetical link between COVID-19 and PD but there is still a 
gap of knowledge in the way of understanding the relationship among them. This hypothesis is also supported by some case reports, stating a rapid onset of PD after infection with SARS-CoV-2 (Eichel et al. 2020; Cartella et al. 2021; Merello et al. 2021).

On the other hand, several viruses including Epstein-Barr, hepatitis $C$, herpes simplex 1, influenza $A$, and varicella-zoster have previously been shown to be related to increasing the risk of diagnosing with PD in the distant future (Henry et al. 2010; Merello et al. 2021). These viruses can directly induce neuronal injury after the infection. For instance, it has been demonstrated that there is a marked increased risk of developing PD after hepatitis $\mathrm{C}$ virus (HCV) infection. This was enabled by the ability of HCV to replicate in CNS (Tsai et al. 2016). The family of Coronaviridae has been known to cause CNS infection (Bergmann et al. 2006), presumably in the case of SARS-CoV-2 via blood-brain barrier (BBB) due to the cytokine storm (CS) (Eldeeb et al. 2020; Sulzer et al. 2020). Moreover, SARS-CoV-2 signature was detected in the autoptic brains of 21 out of 40 patients (53\%) after dying of COVID-19. Although no relationship between the presence of SARS-CoV-2 and the severity of the disease was found, it was proved that SARS-CoV-2 can reach CNS (Matschke et al. 2020). Overall, all the aforementioned pieces of evidence create an urgent need that the possible crosstalk between SARS-CoV-2 and neurodegenerative disorders such as PD should be taken into consideration. Other studies have been carried out assessing other potential comorbidities in respect to COVID-19 including chronic kidney disease (Auwul et al. 2021) and diabetes mellitus (Rahman et al. 2021).

In the present study, we adopted an integrated bioinformatics analysis to scrutinize the common molecular mechanisms involved in COVID-19 and PD pathogenesis and how SARS-CoV-2 can possibly contribute to developing PD whether immediately after contracting COVID-19 or years later (an overview of the present study was shown in the Fig. 1).

\section{Materials And Methods}

\section{Transcriptomic data analysis}

We obtained the transcriptome data from the Gene Expression Omnibus (GEO, https://www.ncbi.nlm.nih.gov/geo/) with accession number GSE152418 (16 PBMCs samples from COVID-19 subjects and 17 normal individuals) (Arunachalam et al. 2020), and GSE165082 (12 PBMCs samples from PD and 14 normal individuals) (Henderson et al. 2021). The R package DESeq2 provided for normalization and differential expression analysis (Love et al. 2014). We used $P$-value $<0.05$ and LogFC $\geq 1$ as thresholds. Common DEGs between two datasets were obtained using the Venny 2.1.0 tool (https://bioinfogp.cnb.csic.es/tools/venny/index.html).

\section{Gene ontology and pathway enrichment analysis}

For the functional annotation and pathway enrichment analysis of the DEGs, Enrichr web utility tools (Kuleshov et al. 2016) were used. WikiPathway and the Kyoto Encyclopedia of Genes and Genomes (KEGG) were used for finding pathway enrichment analysis. Gene Ontology (GO) terms were considered 
in three main categories such as biological process (BP), cellular component (CC), and molecular functions (MF).

\section{Protein-protein interaction network construction and analysis}

GeneMANIA (Warde-Farley et al. 2010) server was used for protein-protein interaction network (PPIN) construction and then the obtained PPIN was analyzed and visualized by Cytoscape version 3.8. We adopted a Hub detection approach called maximum clique centrality (MCC) via cytoHubba plug-in of Cytoscape to retrieve the top 10 hub nodes. MCC is a local-based algorithm which outperforms other methods in hub identification (Chin et al. 2014).

\section{Identification of transcription factors and microRNAs regulating Hub genes}

Transcription factors (TFs) and microRNAs are considered the major regulatory elements of gene expression at both transcription and post-transcription levels (Qin et al. 2020). We have constructed TFHub genes and miRNA-Hub genes regulatory networks with the use of NetworkAnalyst 3.0 to detect important regulatory elements (Zhou et al. 2019). As a TFs database, we used ChEA (Lachmann et al. $2010)$ to create the TF-Hub genes interaction network. To construct the miRNA-Hub genes interaction network, TarBase (Karagkouni et al. 2018) was selected to retrieve interacting miRNAs with regard to hub genes. Following the network's construction, network analysis was carried out to identify core TFs and miRNAs based on the degree.

\section{Results}

\section{Identification of common DEGs between COVID-19 and PD}

We examined transcriptional signatures between COVID-19 $(n=16)$ and healthy controls $(n=17)$. There were 4795 DEGs in COVID-19 versus healthy controls. Also, we obtained DEGs between PD $(n=14)$ and normal subjects $(n=12)$. Our results showed 233 DEGs in PD compared to controls. We detected 81 common DEGs between COVID-19 and PD (Fig. 2). Top ten common DEGs are shown in Table 1.

\section{Pathway enrichment analysis}

Functional annotations of common DEGs indicated involvement in multiple pathways including the complement system, type II interferon signaling (IFNG) pathway, oxidative damage, microglia pathogen phagocytosis pathway, GABAergic synapse (Table 2a). The GO analysis of common DEGs revealed that enriched BPs were mostly involved in the regulation of complement activation, regulation of immune effector process, regulation of humoral immune response, cell junction disassembly, commissural neuron axon guidance, synapse pruning, complement activation, classical pathway, determination of left/right symmetry, negative regulation of humoral immune response mediated by circulating immunoglobulin, humoral immune response mediated by circulating immunoglobulin. The enriched molecular functions were involved in kinase activator activity, protein kinase activator activity, GABA-A receptor activity, neurotransmitter receptor activity involved in regulation of postsynaptic membrane potential, GABA 
receptor activity, transmitter-gated ion channel activity involved in the regulation of postsynaptic membrane potential, protein kinase regulator activity, transmitter-gated ion channel activity, glycerol channel activity, arylesterase activity. CC enriched in GABA-A receptor complex, azurophil granule, collagen-containing extracellular matrix, Golgi lumen, secretory granule lumen, caveola, specific granule lumen, vacuolar lumen, primary lysosome, plasma membrane raft (Table $2 b$ ).

\section{Protein-protein interaction network construction and analysis}

We constructed PPIN, containing 71 nodes and 1369 edges as it was shown in Fig. 3. The PPIN depicts the interaction of common DEGs and was visualized by Cytoscape software. According to Table 3, the ten hub genes based on MCC score are MX Dynamin Like GTPase 1 (MX1), Interferon-alpha inducible protein 27 (IFI27), C1CQ, C1QA, Interferon-alpha inducible protein 6 (IFI6), NFIX, C1S, X-linked inhibitor of apoptosis-associated factor-1 (XAF1), Interferon-alpha inducible protein (IFI35), and Elastase, Neutrophil Expressed (ELANE). These hub genes can potentially be used as drug targets and play a crucial role in maintaining the stability of the network. Therefore, further analysis of these genes is of great importance. For instance, scrutinizing the regulatory interaction of hub genes is recommended.

\section{Regulatory networks}

In order to gain deeper insights into our hub genes, we sought to construct TF-Hub genes and miRNA-Hub genes networks. Figure 4 and Fig. 5 displayed the regulators of the hub genes; TFs and miRNAs respectively. From these regulatory networks, it can be concluded that some regulatory elements are more important and can subsequently interact with more hub genes. In the TFs-Hub genes network, 16 TFs were identified with 3 or more interactions, whereas in miRNAs-Hub genes 29 miRNAs were detected with at least 3 or more interactions. The most connected TFs were SOX2 and XAF1 with the degree of 6 , and $R U N X 1, M I T F, S P I 1$, and $M Y C$ with 5 interactions. The most significant miRNA related to hub genes is hsamir-129-2-3p with a degree of 8. Other major miRNAs are hsa-mir-124-3p, hsa-mir-34a-5p, hsa-mir-21-3p and hsa-mir-27a-5p; each has 6 edges with Hub genes.

\section{Discussion}

The COVID19 outbreak has undoubtedly become an international concern (2021). Some case reports hypothesized rapid onset of PD happens after SARS-CoV-2 infection (Cartella et al. 2021; Merello et al. 2021). However, there is no study aimed to investigate common links between covid-19 and PD yet in an in-silico manner.

In this study, we adopted a network-based approach following transcriptome analysis to detect the common molecular pathways involved in COVID-19 and PD pathogenesis. The analysis demonstrated 81 common DEGs between COVID-19 and PD. We then performed the pathway enrichment analysis of common DEG. Our results showed the complement and coagulation cascades are one of the pathways that are enriched by the common DEGs. The complement system plays a double role in the immune response against SARS-CoV-2 and the pathogenesis of COVID-19 tissue involvement (Gao et al. 2020; 
Diao et al. 2021). Several studies reported complement components to alter within the blood of PD patients (Goldknopf et al. 2006). The type II interferon signaling (IFNG) pathway was also identified. The interferon (IFN) responses constitute the main first line of defense against SARS-CoV-2 (Park and Iwasaki 2020). IFN- $\gamma$ has a role in inflammation and neurodegeneration in PD, as an increase of IFN- $\gamma$ was detected in the serum of PD patients (Baba et al. 2005). Another common pathway was oxidative damage. Oxidative stress most likely impacts COVID-19 pathogenesis by accompanying cell activation (Chernyak et al. 2020). Oxidative stress is one of the mechanisms mentioned in the etiopathogenesis of PD (Dorszewska et al. 2021). Oxidative stress causes damage to key cellular components in the substantia nigra (SN) of PD patients (Dias et al. 2013). We detected microglia pathogen phagocytosis pathway in which microglia by some pathogenic mechanisms, could contribute to the development of post-COVID-19 neurological sequelae and disorders, including PD (Awogbindin et al. 2021). Another enriched pathway was GABAergic synapse. COVID-19-associated inflammation may induce a cortical impairment of GABAergic neurotransmission, possibly representing cognitive fatigue, apathy, and executive deficits (Ortelli et al. 2021). GABA has also been reported to be involved in neurodegenerative disorders such as PD (Muñoz et al. 2020).

The hub genes have been identified from the PPIN to detect major signaling elements that may be used as therapeutic targets for the development of novel drugs to treat COVID-19 patients with PD comorbidity. MX1 is one of the myxovirus resistance genes $(M X)$ which has the antiviral effect against RNA viruses. MX1 expression has been reported to be elevated in COVID-19 patients and conversely decline as age increases. Plus, it can be stimulated in the cytoplasm by IFNs and participates in the cellular antiviral response to SARS-COV-2 (Bizzotto et al. 2020). Furthermore, the accumulation of a-synuclein (a-SYN) in the brain of PD patients induces the expression of MX1. This molecule is involved in PI3K-Akt signaling pathway, cytokine release, immune response IFNs a, $\beta$, and $y$ signaling pathways (Yamada et al. 1994; Qin et al. 2016). It is also a regulator of IFN systems that contributes to CS (Yang et al. 2021). This might facilitate the entry of virus to CNS via BBB. It is noteworthy that BBB was reported to be disrupted in the animal models of PD which can lead to degeneration of neurons in substantia nigra (Al-Bachari et al. 2020). MX1 localized in self-aggregations and generated Lewy bodies and swelling of neuronal processes in the substantia nigra of brain tissues in Parkinson's patients (McDonough et al. 2017). Lewy bodies which contain misfolded proteins can then trigger activation of T-cells (Sulzer et al. 2017). IFNalpha inducible (IRI) family members are closely related to the inflammatory immune response in COVID19 and PD (Shaath et al. 2020). IFI6 is an Immune-associated early predictor for PD (Lei et al. 2020; Yu et al. 2020). IFI35 involved in Type I interferon signaling pathway and have a vital role in inflammation response in SARS-CoV-2 infected cells (Hachim et al. 2020; Ziegler et al. 2020; Ong et al. 2021). On the other hand, IFI35 upregulated in PD patients in response to INFs response (Yu et al. 2020). IFI35 gene is expressed in the stratum and substantia nigra regions of brain and its de novo mutation is contributed to early-onset of PD pathogenesis (Guo et al. 2018). IFI27 is an early predictor for SARS-COV-2 infection and high-level expression of IF127 is associated with the presence of a high viral load (Shojaei et al. 2021). One study found elevated expression of IFI27 after microglial activation and neuroinflammation in progressive neurodegenerative disorders such as PD (Zhou et al. 2015). SARS-CoV-2 infection induces a 
strong activation of major constituents of the human complement subcomponent C1q (C1QA, C1QB, C1QC) (Ramlall et al. 2020; Santiesteban-Lores et al. 2021). These genes are upregulated in the microglia cells in the brain of PD patients. Activation of the complement system improves the removal of pathogens and products of tissue damage from the brain and is related to neuronal cell death in PD (Depboylu et al. 2011; Mariani et al. 2016; Itoh and Voskuhl 2017). ELANE gene codes destructive enzymes named neutrophil elastase that play key role in host defense mechanism. This enzyme is highly overexpressed in naso-oropharyngeal and blood samples of COVID-19 patients. Neutrophil elastase can activate the spike (S) protein and mediate viral entry and pathogenesis of SARS-COV-2 (Belouzard et al. 2010; Akgun et al. 2020; Guéant et al. 2021). After an inflammatory insult to the CNS structure, the expression of neutrophil elastase increases, then degrades basal lamina and extracellular matrix (ECM) molecules, and suppress neurobehavioral recovery mechanisms (Stowe et al. 2009; Stock et al. 2018). Neutrophil Elastase Inhibitors could be new treatment options for COVID-19 patients (Mohamed et al. 2020).

Among these transcription factors, sex-determining region Y-box 2 (SOX2) has a critical role in the development and maintenance of neural stem/progenitor cell populations committed to becoming glial cells. SOX2 inhibits myelination in the peripheral nerves and maintains Schwann cells in a proliferative state, which is also associated with the influx of macrophages and increased neuroinflammation (Roberts et al. 2017). Interestingly, the expression level of SOX2 was found be elevated in the brains of PD patients (Vedam-Mai et al. 2014). Nerve inflammation is one of the important factors in the onset or progression of PD (Pajares et al. 2020). XAF1 is a mitochondrial apoptosis activator that is upregulated in immune cells (T, B, natural killer, and dendritic cells) of COVID-19 patients that may be associated with increased apoptosis of these cells (Zhu et al. 2020; Gao et al. 2021). Furthermore, XAF1 expression is higher in the midbrain of PD patients (Gispert et al. 2015; Santiago and Potashkin 2017). IFN- $\alpha$ and IFN- $\beta$ induced XAF1 mRNA expression and therefore induced cell apoptosis (Leaman et al. 2002). The expression of Runt-related transcription factor 1 (RUNX1) increases after SARS-CoV-2 infection (O'Hare et al. 2021). Interestingly, its overexpression is related to the progression of PD. RUNX1 increases the expression of leucine-rich repeat kinase 2 ( $L r r k 2)$ gene in immune cells and has a critical role in the pathogenesis of familial PD due to developing hyperactive inflammatory phenotype, neuronal toxicity, and cell apoptosis (Cook et al. 2017; Thomsen et al. 2021). Microphthalmia-associated transcription factor (MITF) is one of the key TFs with varying functions in cell homeostasis, cell cycle, and apoptosis. MITF is upregulated in immune cells and worsens severity of infection in an unknown way in COVID-19 patients (Bost et al. 2020; Ding et al. 2021; Jeong et al. 2021). Ubiquitin carboxyl-terminal hydrolase L1 (UCHL1) is expressed in neural cells and inhibits the stability of MITF by binding to the ubiquitinated protein. The ligase activity of UCHL1 is disrupted in PD, resulting in MITF overexpression and cell damage in these patients (Liu et al. 2002; Seo et al. 2017). The E26 transformation-specific (ETS) family transcription factor SPI1 upregulated in PBMCs of COVID-19 patients and is involved in the inflammatory process and modulates host immune systems of these patients (Fagone et al. 2020; Rahman et al. 2021). SPI1 plays a key role in the identity, differentiation, and specialized functions of microglia. Microglia rapidly activates in response to proinflammatory response. These activated microglia are accumulated in 
brain lesions of PD patients. SPI1 has many target functional genes in microglial cells including Spi1, Runx1, Irf8, II34, Aif1, Csf1r, Csf1, Cx3cr1, Tyrobp, and Trem2 (Satoh et al. 2014). SPI1 induces cytokine release and microglial pro-inflammatory response (Pimenova et al. 2021). Therefore, misregulation of SPI1 target genes might lead to the establishment or development of PD due to the accumulation of activated microglia (Satoh et al. 2014). In addition, one multi-omic study identifies a Single-Nucleotide Polymorphism, rs10130373, within a microglia-specific peak, interrupts a SPI1 motif, and interfaces effectively with the promoter of the Rab interactor 3 (RIN3) gene. RIN3 plays an important role in the early endocytic pathway that needs microglial function, thereby, has a particularly critical role in progressive neurodegenerative disease (Kajiho et al. 2003; Corces et al. 2020).

hsa-mir-129-2-3p is the most significant miRNA in miRNA-Hub gene regulatory networks. miR-129 is a brain-enriched miRNA and its level increases in the peripheral blood lymphocytes of PD patients (Qin et al. 2016).

In the present study, an integrated bioinformatics approach was adopted to explore the possible risk of PD development after COVID-19 infection by investigating the common molecular mechanisms. By taking advantage of the holistic viewpoint of systems biology, we were able to consider every aspect of both diseases and infer novel hypotheses. Further supplementary studies need to be conducted to clarify the association between COVID-19 and PD, as at the moment, there is little known regarding both of these disease entities. It is worth mentioning that contracting PD is a complex and age-dependent neurodegenerative disorder. Thus, it is encouraged to investigate infected COVID-19 patients' years after their infection to estimate the probability of getting PD.

\section{Conclusion}

The current study aimed to investigate common regulators between COVID-19 and PD. Overall, our analysis highlights multiple mechanisms such as complement system, oxidative stress, activation microglia, cytokine storm and activation of T-cells by misfolded proteins which might be the potential links between both comorbidities. Nonetheless, as this is a thorough in-silico analysis, the results of this work should be taken into account carefully. Further case reports and follow-up experiments of COVID-19 patients can corroborate these links.

\section{Abbreviations}

COVID-19: coronavirus disease 2019, SARS-CoV-2: severe acute respiratory syndrome coronavirus 2, PD: Parkinson's disease, CNS: central nervous system, HCV: hepatitis $C$ virus, cytokine storm (CS), PBMCs: peripheral blood mononuclear cells, GEO: Gene Expression Omnibus, GO: Gene Ontology, KEGG: Kyoto Encyclopedia of Genes and Genomes, MF: molecular functions, BP: biological process, CC: cellular component, TFs: Transcription factors, PPIN: protein-protein interaction network, ETS: E26 transformation-specific, GABA: gamma-aminobutyric acid, MX1: MX Dynamin Like GTPase 1, myxovirus resistance genes (MX), IFN: interferon, IFI6: Interferon-alpha inducible protein 6, IFI27: Interferon-alpha 
inducible protein 27, IFI35: Interferon-alpha inducible protein 35, XAF1: X-linked inhibitor of apoptosisassociated factor-1, SOX2:sex determining region Y-box 2, RUNX1: Runt-related transcription factor 1 , Lrrk2: leucine-rich repeat kinase 2, MITF: Microphthalmia-associated transcription factor, UCHL1: Ubiquitin carboxyl-terminal hydrolase L1, RIN3: Rab interactor 3

\section{Declarations}

\section{Availability of Data and Materials}

The data used in this study were downloaded from the GEO database.

\section{Compliance with Ethical Standards}

\section{Ethics Approval and Consent to Participate}

Not applicable.

\section{Consent for Publication}

Not applicable.

\section{Code Availability}

The code that supports the findings of this study is available on request from the corresponding author.

\section{Competing Interests}

The authors have no relevant financial or non-financial interests to disclose.

\section{Funding}

The authors declare that no funds, grants, or other support were received during the preparation of this manuscript.

\section{Author Contributions}

All authors contributed to the study conception and design. Material preparation, data collection and analysis were performed by Aria Jahanimoghadam and Hadis Abdolahzade. The first draft of the manuscript was written by Aria Jahanimoghadam, Hadis Abdolahzadeh, Niloofar Khoshdel rad, and all authors commented on previous versions of the manuscript. All authors read and approved the final manuscript.

\section{Acknowledgments}

Not applicable. 


\section{References}

1. Akgun E, Tuzuner MB, Sahin B, et al (2020) Proteins associated with neutrophil degranulation are upregulated in nasopharyngeal swabs from SARS-CoV-2 patients. PLoS One 15:1-10. doi: 10.1371/journal.pone.0240012

2. Al-Bachari S, Naish JH, Parker GJM, et al (2020) Blood-Brain Barrier Leakage Is Increased in Parkinson's Disease. Front Physiol 11:1-12. doi: 10.3389/fphys.2020.593026

3. Arunachalam PS, Wimmers F, Mok CKP, et al (2020) Systems biological assessment of immunity to mild versus severe COVID-19 infection in humans. Science (80- ) 369:1210-1220. doi:

\subsection{6/SCIENCE.ABC6261}

4. Auwul MR, Zhang C, Rahman MR, et al (2021) Network-based transcriptomic analysis identifies the genetic effect of COVID-19 to chronic kidney disease patients: A bioinformatics approach. Saudi J Biol Sci 28:5647-5656. doi: 10.1016/j.sjbs.2021.06.015

5. Awogbindin IO, Ben-Azu B, Olusola BA, et al (2021) Microglial Implications in SARS-CoV-2 Infection and COVID-19: Lessons From Viral RNA Neurotropism and Possible Relevance to Parkinson's Disease. Front Cell Neurosci 15:. doi: 10.3389/fncel.2021.670298

6. Baba Y, Kuroiwa A, Uitti RJ, et al (2005) Alterations of T-lymphocyte populations in Parkinson disease. Park Relat Disord 11:493-498. doi: 10.1016/j.parkreldis.2005.07.005

7. Belouzard S, Madu I, Whittaker GR (2010) Elastase-mediated activation of the severe acute respiratory syndrome coronavirus spike protein at discrete sites within the S2 domain. J Biol Chem 285:22758-22763. doi: 10.1074/jbc.M110.103275

8. Bergmann CC, Lane TE, Stohlman SA (2006) Coronavirus infection of the central nervous system: Host-virus stand-off. Nat Rev Microbiol 4:121-132. doi: 10.1038/nrmicro1343

9. Bizzotto J, Sanchis P, Abbate M, et al (2020) SARS-CoV-2 Infection Boosts MX1 Antiviral Effector in COVID-19 Patients. iScience 23:. doi: 10.1016/j.isci.2020.101585

10. Bost P, Giladi A, Liu Y, et al (2020) Host-Viral Infection Maps Reveal Signatures of Severe COVID-19 Patients. Cell 181:1475-1488.e12. doi: 10.1016/j.cell.2020.05.006

11. Cartella SM, Terranova C, Rizzo V, et al (2021) Covid-19 and Parkinson's disease: an overview. J Neurol 268:4415-4421. doi: 10.1007/s00415-021-10721-4

12. Chams N, Chams S, Badran R, et al (2020) COVID-19: A Multidisciplinary Review. Front Public Heal 8:1-20. doi: 10.3389/fpubh.2020.00383

13. Chernyak B V., Popova EN, Prikhodko AS, et al (2020) COVID-19 and Oxidative Stress. Biochem 85:1543-1553. doi: 10.1134/S0006297920120068

14. Chin $\mathrm{CH}$, Chen $\mathrm{SH}, \mathrm{Wu} \mathrm{HH}$, et al (2014) cytoHubba: Identifying hub objects and sub-networks from complex interactome. BMC Syst Biol 8:1-7. doi: 10.1186/1752-0509-8-S4-S11

15. Cook DA, Kannarkat GT, Cintron AF, et al (2017) LRRK2 levels in immune cells are increased in Parkinson's disease. npj Park Dis 3:1-11. doi: 10.1038/s41531-017-0010-8 
16. Corces MR, Shcherbina A, Kundu S, et al (2020) Single-cell epigenomic analyses implicate candidate causal variants at inherited risk loci for Alzheimer's and Parkinson's diseases. Nat Genet 52:11581168. doi: 10.1038/s41588-020-00721-x

17. Depboylu C, Schäfer MKH, Arias-Carrión O, et al (2011) Possible involvement of complement factor $\mathrm{C} 1 \mathrm{q}$ in the clearance of extracellular neuromelanin from the substantia nigra in Parkinson disease. $J$ Neuropathol Exp Neurol 70:125-132. doi: 10.1097/NEN.0b013e31820805b9

18. Diao $B$, Wang $C$, Wang $R$, et al (2021) Human kidney is a target for novel severe acute respiratory syndrome coronavirus 2 infection. Nat Commun 12:. doi: 10.1038/s41467-021-22781-1

19. Dias V, Junn E, Mouradian MM (2013) The Role of Oxidative Stress in Parkinson's Disease. J Park Dis 3:461-491. doi: $10.3233 / J P D-130230$

20. Ding J, Hostallero DE, El Khili MR, et al (2021) A network-informed analysis of SARS-CoV-2 and hemophagocytic lymphohistiocytosis genes' interactions points to Neutrophil extracellular traps as mediators of thrombosis in COVID-19. PLoS Comput Biol 17:1-23. doi:

10.1371/journal.pcbi.1008810

21. Dorszewska J, Kowalska M, Prendecki M, et al (2021) Oxidative stress factors in Parkinson's disease. Neural Regen Res 16:1383-1391. doi: 10.4103/1673-5374.300980

22. Eichel MEC, Steiner-Birmans B, Janah A, et al (2020) A case of Parkinson disease after SARS-CoV-2 infection. Lancet Neurol 19:804-5

23. Eldeeb MA, Hussain FS, Siddiqi ZA (2020) COVID-19 infection may increase the risk of parkinsonism - Remember the Spanish flu. Cytokine Growth Factor Rev 54:6-7

24. Fagone P, Ciurleo R, Lombardo SD, et al (2020) Transcriptional landscape of SARS-CoV-2 infection dismantles pathogenic pathways activated by the virus, proposes unique sex-specific differences and predicts tailored therapeutic strategies. Autoimmun Rev 19:. doi: 10.1016/j.autrev.2020.102571

25. Gao T, Hu M, Zhang X, et al (2020) Highly pathogenic coronavirus N protein aggravates lung injury by MASP-2-mediated complement over-activation. medRxiv. doi: 10.1101/2020.03.29.20041962

26. Gao X, Liu Y, Zou S, et al (2021) Genome-wide screening of SARS-CoV-2 infection-related genes based on the blood leukocytes sequencing data set of of patients with COVID-19. J Med Virol 93:. doi: $10.1002 / j m v .27093$

27. Gispert S, Brehm N, Weil J, et al (2015) Potentiation of neurotoxicity in double-mutant mice with Pink1 ablation and A53T-SNCA overexpression. Hum Mol Genet 24:1061-1076. doi:

10.1093/hmg/ddu520

28. Goldknopf IL, Sheta EA, Bryson J, et al (2006) Complement C3c and related protein biomarkers in amyotrophic lateral sclerosis and Parkinson's disease. Biochem Biophys Res Commun 342:10341039. doi: 10.1016/j.bbrc.2006.02.051

29. Guéant JL, Guéant-Rodriguez RM, Fromonot J, et al (2021) Elastase and exacerbation of neutrophil innate immunity are involved in multi-visceral manifestations of COVID-19. Allergy Eur. J. Allergy Clin. Immunol. 76:1846-1858 
30. Guo JF, Zhang L, Li K, et al (2018) Coding mutations in NUS1 contribute to Parkinson's disease. Proc Natl Acad Sci U S A 115:11567-11572. doi: 10.1073/pnas.1809969115

31. Hachim MY, Al Heialy S, Hachim IY, et al (2020) Interferon-Induced Transmembrane Protein (IFITM3) Is Upregulated Explicitly in SARS-CoV-2 Infected Lung Epithelial Cells. Front Immunol 11:1-9. doi: 10.3389/fimmu.2020.01372

32. Hayes MT (2019) Parkinson's Disease and Parkinsonism. Am J Med 132:802-807. doi: 10.1016/j.amjmed.2019.03.001

33. Henderson AR, Wang Q, Meechoovet B, et al (2021) DNA Methylation and Expression Profiles of Whole Blood in Parkinson's Disease. Front Genet 12:1-17. doi: 10.3389/fgene.2021.640266

34. Henry J, Smeyne RJ, Jang H, et al (2010) Parkinsonism and neurological manifestations of influenza throughout the 20th and 21st centuries. Park Relat Disord 16:566-571. doi:

10.1016/j.parkreldis.2010.06.012

35. Itoh Y, Voskuhl RR (2017) Cell specificity dictates similarities in gene expression in multiple sclerosis, Parkinson's disease, and Alzheimer's disease. PLoS One 12:1-11. doi:

10.1371/journal.pone.0181349

36. Jeong HH, Jia J, Dai Y, et al (2021) Investigating cellular trajectories in the severity of covid-19 and their transcriptional programs using machine learning approaches. Genes (Basel) 12:. doi: 10.3390/genes 12050635

37. Kajiho H, Saito K, Tsujita K, et al (2003) RIN3: A novel Rab5 GEF interacting with amphiphysin II involved in the early endocytic pathway. J Cell Sci 116:4159-4168. doi: 10.1242/jcs.00718

38. Kalia L V., Lang AE (2016) Parkinson disease in 2015: Evolving basic, pathological and clinical concepts in PD. Nat Rev Neurol 12:2-3. doi: 10.1038/nrneurol.2015.249

39. Karagkouni D, Paraskevopoulou MD, Chatzopoulos S, et al (2018) DIANA-TarBase v8: A decade-long collection of experimentally supported miRNA-gene interactions. Nucleic Acids Res 46:D239-D245. doi: $10.1093 /$ nar/gkx1141

40. Khorsand B, Savadi A, Naghibzadeh M (2020) SARS-CoV-2-human protein-protein interaction network. Informatics Med Unlocked 20:100413. doi: 10.1016/j.imu.2020.100413

41. Kuleshov M V., Jones MR, Rouillard AD, et al (2016) Enrichr: a comprehensive gene set enrichment analysis web server 2016 update. Nucleic Acids Res 44:W90-W97. doi: 10.1093/nar/gkw377

42. Lachmann A, Xu H, Krishnan J, et al (2010) ChEA: Transcription factor regulation inferred from integrating genome-wide ChIP-X experiments. Bioinformatics 26:2438-2444. doi:

10.1093/bioinformatics/btq466

43. Leaman DW, Chawla-Sarkar M, Vyas K, et al (2002) Identification of X-linked inhibitor of apoptosisassociated factor- 1 as an interferon-stimulated gene that augments trail Apo2L-induced apoptosis. $J$ Biol Chem 277:28504-28511. doi: 10.1074/jbc.M204851200

44. Lei K, Zhang L, He Y, et al (2020) Immune-associated biomarkers for early diagnosis of Parkinson's disease based on hematological IncRNA-mRNA co-expression. Biosci Rep 40:1-13. doi: 10.1042/BSR20202921

Page 12/24 
45. Liu Y, Fallon L, Lashuel HA, et al (2002) The UCH-L1 gene encodes two opposing enzymatic activities that affect a-synuclein degradation and Parkinson's disease susceptibility. Cell 111:209-218. doi: 10.1016/S0092-8674(02)01012-7

46. Love M, Huber W, Anders S (2014) Moderated estimation of fold change and dispersion for RNA-Seq data with DESeq2

47. Mariani E, Frabetti F, Tarozzi A, et al (2016) Meta-analysis of Parkinson's disease transcriptome data using TRAM software: Whole substantia nigra tissue and single dopamine neuron differential gene expression. PLoS One 11:1-21. doi: 10.1371/journal.pone.0161567

48. Matschke J, Lütgehetmann M, Hagel C, et al (2020) Neuropathology of patients with COVID-19 in Germany: a post-mortem case series. Lancet Neurol 19:919-929. doi: 10.1016/S14744422(20)30308-2

49. McDonough A, Lee R V., Weinstein JR (2017) Microglial Interferon Signaling and White Matter. Neurochem Res 42:2625-2638. doi: 10.1007/s11064-017-2307-8

50. Merello M, Bhatia KP, Obeso JA (2021) SARS-CoV-2 and the risk of Parkinson's disease: facts and fantasy. Lancet Neurol 20:94-95. doi: 10.1016/S1474-4422(20)30442-7

51. Mohamed MMA, El-Shimy IA, El-Shimy IA, Hadi MA (2020) Neutrophil Elastase Inhibitors: A potential prophylactic treatment option for SARS-CoV-2-induced respiratory complications? Crit Care 24:9-11. doi: 10.1186/s13054-020-03023-0

52. Muñoz MD, de la Fuente N, Sánchez-capelo A (2020) TGF- $\beta / S m a d 3$ signalling modulates GABA neurotransmission: Implications in Parkinson's disease. Int J Mol Sci 21:. doi: 10.3390/ijms21020590

53. O’Hare M, Amarnani D, Whitmore HAB, et al (2021) Targeting Runt-Related Transcription Factor 1 Prevents Pulmonary Fibrosis and Reduces Expression of Severe Acute Respiratory Syndrome Coronavirus 2 Host Mediators. Am J Pathol 191:1193-1208. doi: 10.1016/j.ajpath.2021.04.006

54. Olsen LK, Dowd E, McKernan DP (2018) A role for viral infections in Parkinson's etiology? Neuronal Signal 2:1-14. doi: 10.1042/ns20170166

55. Ong EZ, Kalimuddin S, Chia WC, et al (2021) Temporal dynamics of the host molecular responses underlying severe COVID-19 progression and disease resolution. EBioMedicine 65:103262. doi: 10.1016/j.ebiom.2021.103262

56. Ortelli P, Ferrazzoli D, Sebastianelli L, et al (2021) Neuropsychological and neurophysiological correlates of fatigue in post-acute patients with neurological manifestations of COVID-19: Insights into a challenging symptom. J Neurol Sci 420:117271. doi: 10.1016/j.jns.2020.117271

57. Pajares M, I Rojo A, Manda G, et al (2020) Inflammation in Parkinson's Disease: Mechanisms and Therapeutic Implications. Cells 9:1-32. doi: 10.3390/cells9071687

58. Park A, Iwasaki A (2020) Type I and Type III Interferons - Induction, Signaling, Evasion, and Application to Combat COVID-19. Cell Host Microbe 27:870-878. doi: 10.1016/j.chom.2020.05.008

59. Pimenova AA, Herbinet M, Gupta I, et al (2021) Alzheimer's-associated PU.1 expression levels regulate microglial inflammatory response. Neurobiol Dis 148:105217. doi: 
10.1016/j.nbd.2020.105217

60. Qin G, Mallik S, Mitra R, et al (2020) MicroRNA and transcription factor co-regulatory networks and subtype classification of seminoma and non-seminoma in testicular germ cell tumors. Sci Rep 10:114. doi: $10.1038 / \mathrm{s} 41598-020-57834-w$

61. Qin H, Buckley JA, Li X, et al (2016) Inhibition of the JAK/STAT pathway protects against a-synucleininduced neuroinflammation and dopaminergic neurodegeneration. J Neurosci 36:5144-5159. doi: 10.1523/JNEUROSCI.4658-15.2016

62. Rahman MR, Islam T, Shahjaman M, et al (2021) Discovering common pathogenetic processes between COVID-19 and diabetes mellitus by differential gene expression pattern analysis. Brief Bioinform 22:1-12. doi: 10.1093/bib/bbab262

63. Ramlall V, Thangaraj PM, Meydan C, et al (2020) Immune complement and coagulation dysfunction in adverse outcomes of SARS-CoV-2 infection. Nat Med 26:1609-1615. doi: 10.1038/s41591-020$1021-2$

64. Raza C, Anjum R, Shakeel N ul A (2019) Parkinson's disease: Mechanisms, translational models and management strategies. Life Sci 226:77-90. doi: 10.1016/j.Ifs.2019.03.057

65. Roberts SL, Dun XP, Doddrell RDS, et al (2017) Sox2 expression in schwann cells inhibits myelination in vivo and induces influx of macrophages to the nerve. Dev 144:3114-3125. doi:

10.1242/dev.150656

66. Santiago JA, Potashkin JA (2017) Blood transcriptomic meta-analysis identifies dysregulation of hemoglobin and iron metabolism in Parkinson' disease. Front Aging Neurosci 9:1-8. doi: 10.3389/fnagi.2017.00073

67. Santiesteban-Lores LE, Amamura TA, da Silva TF, et al (2021) A double edged-sword - The Complement System during SARS-CoV-2 infection. Life Sci 272:1-9. doi: 10.1016/j.lfs.2021.119245

68. Satoh JI, Asahina N, Kitano S, Kino Y (2014) A comprehensive profile of Chlp-Seq-Based PU.1/Spi1 target genes in microglia. Gene Regul Syst Bio 8:127-139. doi: 10.4137/GRSB.S19711

69. Seo EY, Jin SP, Sohn KC, et al (2017) UCHL1 Regulates Melanogenesis through Controlling MITF Stability in Human Melanocytes. J Invest Dermatol 137:1757-1765. doi: 10.1016/j.jid.2017.03.024

70. Shaath H, Vishnubalaji R, Elkord E, Alajez NM (2020) Single-Cell Transcriptome Analysis Highlights a Role for Neutrophils and Inflammatory Macrophages in the Pathogenesis of Severe COVID-19. Cells 9:1-19. doi: 10.3390/cells9112374

71. Shojaei M, Shamshirian A, Monkman J, et al (2021) IFI27 transcription is an early predictor for COVID-19 outcomes; a multi-cohort observational study. medRxiv 2021.10.29.21265555. doi: 10.1101/2021.10.29.21265555

72. Song E, Zhang C, Israelow B, et al (2021) Neuroinvasion of SARS-CoV-2 in human and mouse brain. J Exp Med 218:. doi: 10.1084/JEM.20202135

73. Stock AJ, Kasus-Jacobi A, Pereira HA (2018) The role of neutrophil granule proteins in neuroinflammation and Alzheimer's disease. J Neuroinflammation 15:1-15. doi: 10.1186/s12974018-1284-4 
74. Stowe AM, Adair-Kirk TL, Gonzales ER, et al (2009) Neutrophil elastase and neurovascular injury following focal stroke and reperfusion. Neurobiol Disord 35:82-90. doi:

10.1016/j.nbd.2009.04.006. Neutrophil

75. Sulzer D, Alcalay RN, Garretti F, et al (2017) T cells from patients with Parkinson's disease recognize a-synuclein peptides. Nature 546:656-661. doi: 10.1038/nature22815

76. Sulzer D, Antonini A, Leta V, et al (2020) COVID-19 and possible links with Parkinson's disease and parkinsonism: from bench to bedside. npj Park Dis 6:. doi: 10.1038/s41531-020-00123-0

77. Szcześniak D, Gładka A, Misiak B, et al (2021) The SARS-CoV-2 and mental health: From biological mechanisms to social consequences. Prog Neuro-Psychopharmacology Biol Psychiatry 104:. doi: 10.1016/j.pnpbp.2020.110046

78. Thomsen I, Kunowska N, de Souza R, et al (2021) RUNX1 controls the dynamics of cell cycle entry of naïve resting $B$ cells by regulating expression of cell cycle and immunomodulatory genes in response to BCR stimulation

79. Tsai HH, Liou HH, Muo $\mathrm{CH}$, et al (2016) Hepatitis $\mathrm{C}$ virus infection as a risk factor for Parkinson disease: a nationwide cohort study. Neurology 86:840-846. doi: 10.1212/WNL.0000000000002307

80. Vedam-Mai V, Gardner B, Okun MS, et al (2014) Increased precursor cell proliferation after deep brain stimulation for Parkinson's disease: A human study. PLoS One 9:1-8. doi:

10.1371/journal.pone.0088770

81. Warde-Farley D, Donaldson SL, Comes O, et al (2010) The GeneMANIA prediction server: Biological network integration for gene prioritization and predicting gene function. Nucleic Acids Res 38:214220. doi: $10.1093 /$ nar/gkq537

82. Yamada T, Horisberger M., Kawaguchi N, et al (1994) Immunohistochemistry using antibodies to ainterferon and its induced protein, MxA, in Alzheimer's and Parkinson's disease brain tissues. Neurosci Lett 181:61-64

83. Yang L, Xie X, Tu Z, et al (2021) The signal pathways and treatment of cytokine storm in COVID-19. Signal Transduct Target Ther 6:1-20. doi: 10.1038/s41392-021-00679-0

84. Yu F, Le Z Sen, Chen LH, et al (2020) Identification of Biomolecular Information in Rotenone-Induced Cellular Model of Parkinson's Disease by Public Microarray Data Analysis. J Comput Biol 27:888903. doi: $10.1089 / \mathrm{cmb} .2019 .0151$

85. Zhou G, Soufan O, Ewald J, et al (2019) NetworkAnalyst 3.0: A visual analytics platform for comprehensive gene expression profiling and meta-analysis. Nucleic Acids Res 47:W234-W241. doi: $10.1093 /$ nar/gkz240

86. Zhou X, Zöller T, Krieglstein K, Spittau B (2015) TGFß1 inhibits IFNY-mediated microglia activation and protects mDA neurons from IFNY-driven neurotoxicity. J Neurochem 134:125-134

87. Zhu L, Yang P, Zhao Y, et al (2020) Single-Cell Sequencing of Peripheral Mononuclear Cells Reveals Distinct Immune Response Landscapes of COVID-19 and Influenza Patients. Immunity 53:685696.e3. doi: 10.1016/j.immuni.2020.07.009 
88. Ziegler CGK, Allon SJ, Nyquist SK, et al (2020) SARS-CoV-2 Receptor ACE2 Is an InterferonStimulated Gene in Human Airway Epithelial Cells and Is Detected in Specific Cell Subsets across Tissues. Cell 181:1016-1035.e19. doi: 10.1016/j.cell.2020.04.035

89. (2021) General's opening remarks at the media briefing on COVID-19-11 March 2020. In: WHO. https://www.who.int/director-general/speeches/detail/who-director-general-s-opening-remarks-at-themedia-briefing-on-covid-19-11-march-2020

\section{Tables}

Table 1

Top ten common DEGs between COVID-19 and PD

\begin{tabular}{|lll|}
\hline $\begin{array}{l}\text { The } \\
\text { common }\end{array}$ & Log FC & \\
\cline { 2 - 3 } DEGs & $\begin{array}{l}\text { GSE152418 (COVID-19 versus healthy } \\
\text { control) }\end{array}$ & $\begin{array}{l}\text { GSE165082 (Parkinson versus healthy } \\
\text { control) }\end{array}$ \\
\hline ISG15 & 1.2 & -1.3 \\
\hline GABRD & 1.8 & -2.1 \\
\hline C1QC & 3.5 & -1.05 \\
\hline C1QB & 2.9 & -1.2 \\
\hline IFI6 & 2.05 & -1.2 \\
\hline A3GALT2 & 2.08 & 1.04 \\
\hline VCAM1 & -1.2 & 2.9 \\
\hline AQP10 & 1.9 & -1.2 \\
\hline ACTG1P25 & 1.1 & -1.2 \\
\hline C4BPA & 1.1 & -1.4 \\
\hline
\end{tabular}


Table 2a

Top ten molecular pathways enriched by 81 common DEGs in COVID-19 and PD

\begin{tabular}{|c|c|c|c|c|}
\hline Source & Pathways & P-value & Count & Genes \\
\hline $\begin{array}{l}\text { Wiki } \\
\text { Pathway }\end{array}$ & $\begin{array}{l}\text { Complement and } \\
\text { Coagulation } \\
\text { Cascades WP558 }\end{array}$ & 0.001682 & 3 & C1QB;SERPING1;C1QC \\
\hline \multirow{9}{*}{ Pathway } & $\begin{array}{l}\text { Complement } \\
\text { Activation WP545 }\end{array}$ & 0.003550 & 2 & C1QB;C1QC \\
\hline & $\begin{array}{l}\text { Complement } \\
\text { system WP2806 }\end{array}$ & 0.007179 & 3 & SERPING1;C4BPA;ELANE \\
\hline & $\begin{array}{l}\text { Type II interferon } \\
\text { signaling (IFNG) } \\
\text { WP619 }\end{array}$ & 0.009842 & 2 & IFI6;ISG15 \\
\hline & $\begin{array}{l}\text { miRNAs } \\
\text { involvement in the } \\
\text { immune response } \\
\text { in sepsis WP4329 }\end{array}$ & 0.009842 & 2 & VCAM1;ELANE \\
\hline & $\begin{array}{l}\text { Oxidative Damage } \\
\text { WP3941 }\end{array}$ & 0.011437 & 2 & C1QB;C1QC \\
\hline & $\begin{array}{l}\text { Microglia } \\
\text { Pathogen } \\
\text { Phagocytosis } \\
\text { Pathway WP3937 }\end{array}$ & 0.011437 & 2 & C1QB;C1QC \\
\hline & $\begin{array}{l}\text { Development of } \\
\text { ureteric collection } \\
\text { system WP5053 }\end{array}$ & 0.015565 & 2 & WNT11;SMO \\
\hline & $\begin{array}{l}\text { Prader-Willi and } \\
\text { Angelman } \\
\text { Syndrome WP3998 }\end{array}$ & 0.025409 & 2 & GABRR2;GABRD \\
\hline & $\begin{array}{l}\text { Non-genomic } \\
\text { actions of } 1,25 \\
\text { dihydroxyvitamin } \\
\text { D3 WP4341 }\end{array}$ & 0.033623 & 2 & RSAD2;ISG15 \\
\hline \multirow[t]{5}{*}{ KEGG } & Pertussis & 0.000256 & 4 & C1QB;SERPING1;C4BPA;C1QC \\
\hline & $\begin{array}{l}\text { Complement and } \\
\text { coagulation } \\
\text { cascades }\end{array}$ & 0.000394 & 4 & C1QB;SERPING1;C4BPA;C1QC \\
\hline & $\begin{array}{l}\text { Systemic lupus } \\
\text { erythematosus }\end{array}$ & 0.002210 & 4 & C1QB;CTSG;ELANE;C1QC \\
\hline & $\begin{array}{l}\text { Neuroactive ligand- } \\
\text { receptor }\end{array}$ & 0.002609 & 6 & GABRR2;CHRND;GRID1;LPAR1;CTSG;GABRD \\
\hline & $\begin{array}{l}\text { Staphylococcus } \\
\text { aureus infection }\end{array}$ & 0.006778 & 3 & C1QB;DEFA4;C1QC \\
\hline
\end{tabular}




\begin{tabular}{|lllll|}
\hline Source & Pathways & P-value & Count & Genes \\
\hline $\begin{array}{l}\text { Transcriptional } \\
\text { misregulation }\end{array}$ & 0.007708 & 4 & ETV7;DEFA4;ERG;ELANE \\
\hline $\begin{array}{l}\text { Nicotine addiction } \\
\begin{array}{l}\text { Basal cell } \\
\text { carcinoma }\end{array}\end{array}$ & 0.011437 & 2 & GABRR2;GABRD \\
$\begin{array}{l}\text { GABAergic } \\
\text { synapse }\end{array}$ & 0.026977 & 2 & WNT11;SMO \\
$\begin{array}{l}\text { Morphine } \\
\text { addiction }\end{array}$ & 0.050585 & 2 & GABRR2;GABRD \\
\hline
\end{tabular}


Table $2 b$

GO enrichment analysis of 81 common DEGs in COVID-19 and PD

\begin{tabular}{|c|c|c|c|c|}
\hline & Term & P-value & Count & Genes \\
\hline \multirow[t]{10}{*}{ BP } & $\begin{array}{l}\text { regulation of } \\
\text { complement activation } \\
\text { (G0:0030449) }\end{array}$ & 0.000049 & 4 & C1QB;SERPING1;C4BPA;C1QC \\
\hline & $\begin{array}{l}\text { regulation of immune } \\
\text { effector process } \\
\text { (GO:0002697) }\end{array}$ & 0.000062 & 4 & C1QB;SERPING1;C4BPA;C1QC \\
\hline & $\begin{array}{l}\text { regulation of humoral } \\
\text { immune response } \\
\text { (GO:0002920) }\end{array}$ & 0.000067 & 4 & C1QB;SERPING1;C4BPA;C1QC \\
\hline & $\begin{array}{l}\text { cell junction disassembly } \\
\text { (G0:0150146) }\end{array}$ & 0.00024 & 2 & C1QB;C1QC \\
\hline & $\begin{array}{l}\text { commissural neuron } \\
\text { axon guidance } \\
\text { (G0:0071679) }\end{array}$ & 0.00044 & 2 & SMO;NFIB \\
\hline & $\begin{array}{l}\text { synapse pruning } \\
(\mathrm{GO}: 0098883)\end{array}$ & 0.00057 & 2 & C1QB;C1QC \\
\hline & $\begin{array}{l}\text { complement activation, } \\
\text { classical pathway } \\
\text { (G0:0006958) }\end{array}$ & 0.00057 & 2 & C1QB;C1QC \\
\hline & $\begin{array}{l}\text { determination of } \\
\text { left/right symmetry } \\
\text { (G0:0007368) }\end{array}$ & 0.00065 & 3 & DNAH11;SMO;FOXJ1 \\
\hline & $\begin{array}{l}\text { negative regulation of } \\
\text { humoral immune } \\
\text { response mediated by } \\
\text { circulating } \\
\text { immunoglobulin } \\
\text { (G0:0002924) }\end{array}$ & 0.00071 & 2 & FOXJ1;C4BPA \\
\hline & $\begin{array}{l}\text { humoral immune } \\
\text { response mediated by } \\
\text { circulating } \\
\text { immunoglobulin } \\
\text { (G0:0002455) }\end{array}$ & 0.00087 & 2 & C1QB;C1QC \\
\hline \multirow[t]{3}{*}{ MF } & $\begin{array}{l}\text { kinase activator activity } \\
\text { (GO:0019209) }\end{array}$ & 0.00026 & 3 & WNT11;SPDYA;GPRC5D \\
\hline & $\begin{array}{l}\text { protein kinase activator } \\
\text { activity (GO:0030295) }\end{array}$ & 0.002133 & 3 & WNT11;SPDYA;GPRC5D \\
\hline & $\begin{array}{l}\text { GABA-A receptor activity } \\
(\text { GO:0004890) }\end{array}$ & 0.002649 & 2 & GABRR2;GABRD \\
\hline
\end{tabular}




\begin{tabular}{|c|c|c|c|c|}
\hline & Term & P-value & Count & Genes \\
\hline & $\begin{array}{l}\text { neurotransmitter receptor } \\
\text { activity involved in } \\
\text { regulation of } \\
\text { postsynaptic membrane } \\
\text { potential (GO:0099529) }\end{array}$ & 0.003236 & 2 & CHRND;GRID1 \\
\hline & $\begin{array}{l}\text { GABA receptor activity } \\
\text { (G0:0016917) }\end{array}$ & 0.00355 & 2 & GABRR2;GABRD \\
\hline & $\begin{array}{l}\text { transmitter-gated ion } \\
\text { channel activity involved } \\
\text { in regulation of } \\
\text { postsynaptic membrane } \\
\text { potential (GO:1904315) }\end{array}$ & 0.006547 & 2 & CHRND;GRID1 \\
\hline & $\begin{array}{l}\text { protein kinase regulator } \\
\text { activity (GO:0019887) }\end{array}$ & 0.007384 & 3 & WNT11;SPDYA;GPRC5D \\
\hline & $\begin{array}{l}\text { transmitter-gated ion } \\
\text { channel activity } \\
\text { (GO:0022824) }\end{array}$ & 0.008356 & 2 & CHRND;GRID1 \\
\hline & $\begin{array}{l}\text { glycerol channel activity } \\
\text { (G0:0015254) }\end{array}$ & 0.020088 & 1 & AQP10 \\
\hline & $\begin{array}{l}\text { arylesterase activity } \\
\text { (G0:0004064) }\end{array}$ & 0.024058 & 1 & CA1 \\
\hline CC & $\begin{array}{l}\text { GABA-A receptor complex } \\
\text { (GO:1902711) }\end{array}$ & 0.002649 & 2 & GABRR2;GABRD \\
\hline & $\begin{array}{l}\text { azurophil granule } \\
\text { (GO:0042582) }\end{array}$ & 0.003635 & 4 & CEACAM6;DEFA4;CTSG;ELANE \\
\hline & $\begin{array}{l}\text { collagen-containing } \\
\text { extracellular matrix } \\
\text { (G0:0062023) }\end{array}$ & 0.004433 & 6 & C1QB;SERPING1;CTSG;CSPG4;ELANE;C1QC \\
\hline & $\begin{array}{l}\text { Golgi lumen } \\
\text { (GO:0005796) }\end{array}$ & 0.007805 & 3 & DEFA4;CSPG4;MUC5B \\
\hline & $\begin{array}{l}\text { secretory granule lumen } \\
\text { (G0:0034774) }\end{array}$ & 0.009194 & 5 & DEFA4;SELENOP;SERPING1;CTSG;ELANE \\
\hline & caveola (G0:0005901) & 0.02464 & 2 & SMO;KCNA5 \\
\hline & $\begin{array}{l}\text { specific granule lumen } \\
\text { (GO:0035580) }\end{array}$ & 0.026188 & 2 & DEFA4;ELANE \\
\hline & $\begin{array}{l}\text { vacuolar lumen } \\
\text { (GO:0005775) }\end{array}$ & 0.027664 & 3 & CTSG;CSPG4;ELANE \\
\hline
\end{tabular}

Note: BP, biological processes; MF, molecular functions; CC, cellular components 


\begin{tabular}{|llll|}
\hline Term & P-value & Count & Genes \\
\hline $\begin{array}{l}\text { primary lysosome } \\
\text { (GO:0005766) }\end{array}$ & 0.043669 & 1 & DEFA4 \\
\hline $\begin{array}{l}\text { plasma membrane raft } \\
\text { (GO:0044853) }\end{array}$ & 0.043678 & 2 & SMO;KCNA5 \\
\hline Note: BP, biological processes; MF, molecular functions; CC, cellular components \\
\hline
\end{tabular}

Table 3

Summary of hub nodes

\begin{tabular}{|ll|}
\hline Hubs & MCC \\
\hline MX1 & 5 \\
\hline IFI27 & 4 \\
\hline C1QC & 3 \\
\hline C1QA & 3 \\
\hline IFI6 & 3 \\
\hline NFIX & 2 \\
\hline C1S & 2 \\
\hline XAF1 & 2 \\
\hline IFI35 & 2 \\
\hline ELANE & 2 \\
\hline Note: MCC, maximum clique centrality \\
\hline
\end{tabular}

Figures 


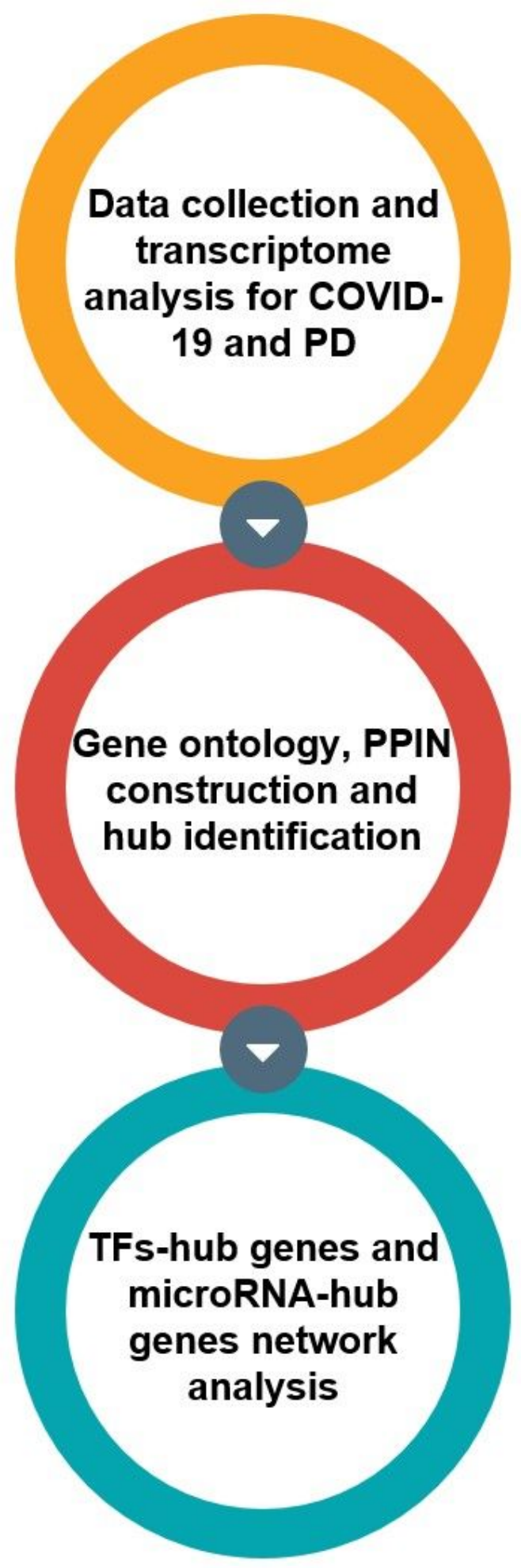

Figure 1

Flow chart of steps conducted in the study 
GSE152418

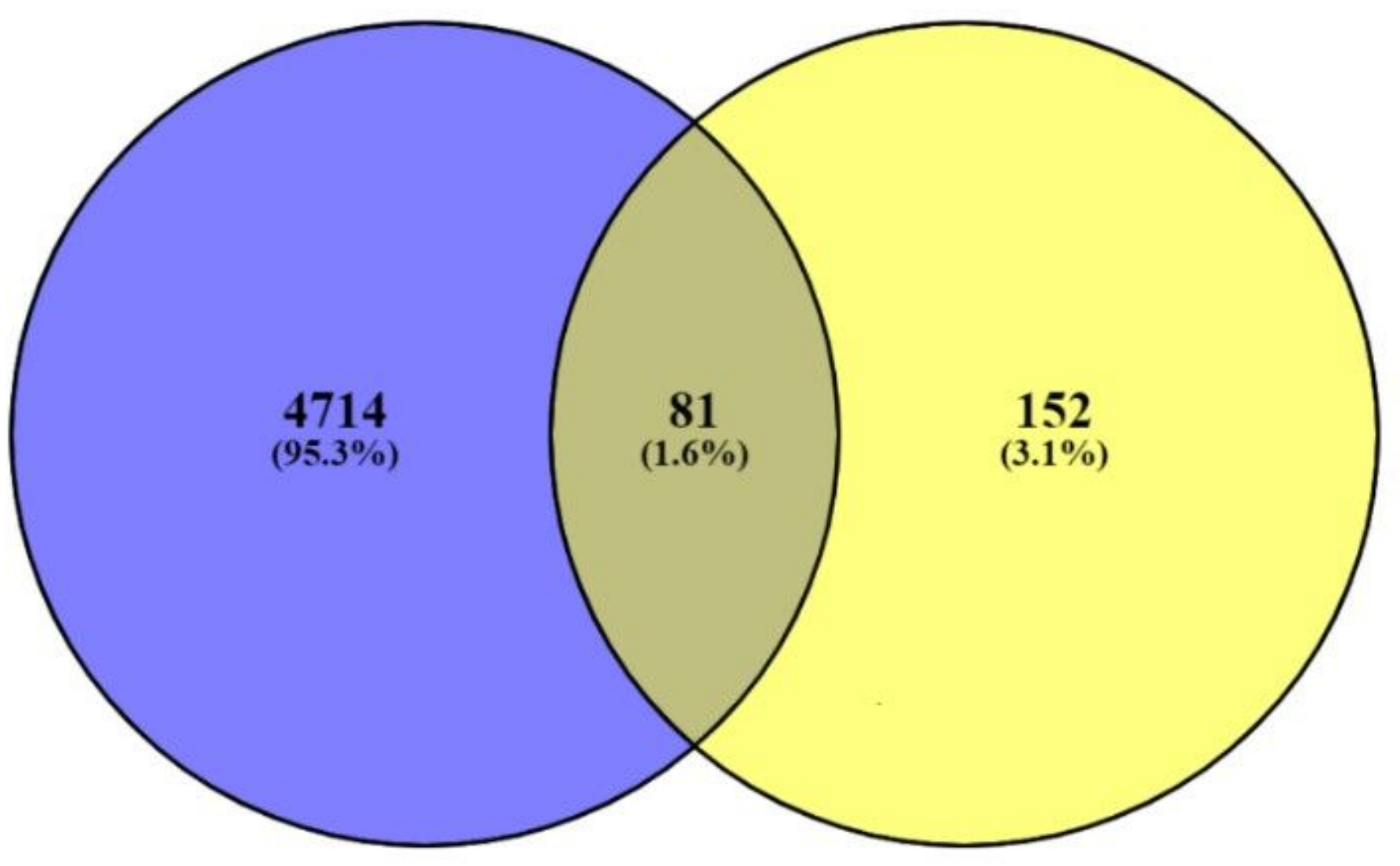

Figure 2

Venn diagram shows common DGEs between Covid-19 and PD 


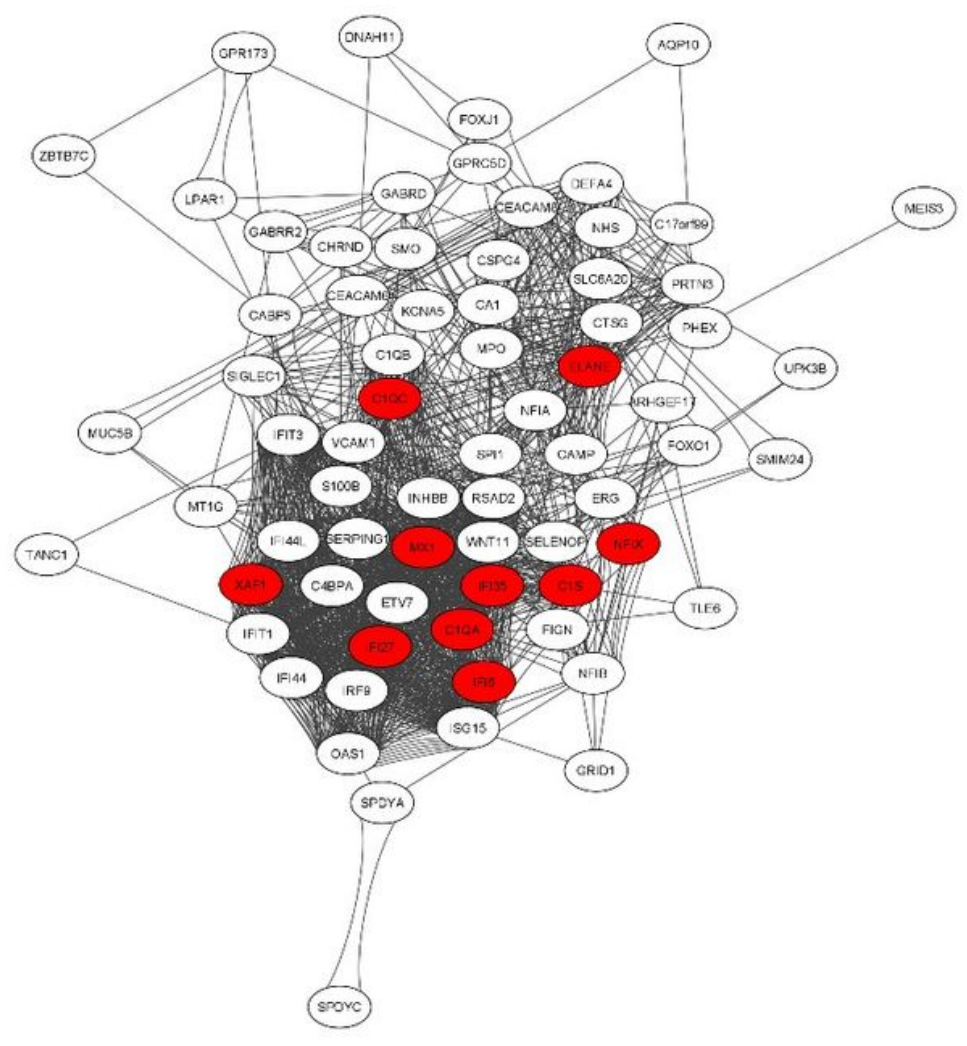

Figure 3

PPIN of common DEGs. Green nodes indicate top 10 hub genes identified by MCC

Figure 4

TFs-hub genes regulatory network acquired from Network Analysis web server. Square nodes representing TFs and circle nodes are stand for Hub genes

Figure 5

miRNAs-hub genes regulatory network acquired from Network Analysis web server. Square nodes represent miRNAs that regulate circle nodes which denote Hub genes 